\title{
Effects of fetal striatal transplants on motor asymmetry in ibotenic acid model of Huntington's disease
}

\author{
CESARIO V. BORLONGAN, STEPHEN G. POULOS, \\ DAVID W. CAHILL, and PAUL R. SANBERG \\ University of South Florida College of Medicine, Tampa, Florida
}

\begin{abstract}
Recently, we proposed the elevated body swing test (EBST) as a drug-free behavioral parameter of motor asymmetry in animals with unilateral striatal lesions. We demonstrated that rats, receiving unilateral excitotoxic lesions in the striatum, exhibit a biased swing behavior (ipsilateral to the lesion) which is stable up to 56 days postlesion. To further extend the efficacy of the EBST in the present study, we monitored the recovery of the biased swing behavior following fetal striatal transplants in animals unilaterally lesioned with ibotenic acid in the striatum. At 2 months postlesion, Sprague-Dawley male rats that displayed $70 \%$ or greater biased swing behavior were transplanted with either cell suspension of rat fetal striatal lateral eminence (16-day-old gestational age) or hibernation medium. EBST was conducted as early as 7 days posttransplant and once a week thereafter. Animals transplanted with the fetal tissue showed a normalization of the asymmetrical swing behavior (at least 50\% to each side) throughout the posttransplant period. Conversely, animals that were transplanted solely with medium continued to display a biased swing behavior. Thus, the EBST is a sensitive behavioral test in characterizing recovery of motor function in striatal lesioned animals that have received fetal striatal transplants.
\end{abstract}

The subsequent normalization of motor asymmetry in animal models of neurodegenerative disorders has been widely used as the primary behavioral index of successful brain insult and treatment intervention, respectively. For example, asymmetrical motor behavior has been documented in rats following either unilateral excitoxic lesions of the striatum (Norman, Calderon, Giordano, \& Sanberg, 1988; Ungerstedt \& Arbuthnott, 1972) or unilateral 6hydroxydopamine destruction of the nigrostriatal dopaminergic pathway (Borlongan, Randall, Cahill, \& Sanberg, 1995; Borlongan \& Sanberg, 1995; Norman et al., 1988; Sanberg, Wictorin, \& Isacson, 1994). Stereotypical turning behavior in response to a dopamine (DA) agonist is the conventional behavioral test for characterizing the asymmetrical motor behavior in lesioned rats (Ungerstedt \& Arbuthnott, 1972). However, the inherent problem in this druginduced behavioral test is that the observed response to the drug may be a pharmacological reaction (Hattori, Li, Matsui, \& Nishino, 1993; Kolb \& Whishaw, 1985) and thus may not fully reflect a true asymmetrical behavior.

To enable better correlation with a human motor dysfunction, asymmetrical motor behavior may best be evaluated by a drug-free behavioral test. Recently, we demonstrated that the elevated body swing test (EBST) is a

This study was supported by a grant from the University of South Florida President's Council. Correspondence concerning this article should be sent to P. R. Sanberg, Division of Neurological Surgery, Department of Surgery, University of South Florida, College of Medicine, 12901 Bruce B. Downs Blvd., Tampa, FL 33612 (e-mail: psanberg@) coml.med.usf.edu). sensitive behavioral assay of motor asymmetry in striatal lesioned animals (Borlongan, Randall, et al., 1995; Borlongan \& Sanberg, 1995). For example, animals with unilateral 6-hydroxydopamine lesions in the substantia nigra (a Parkinson's disease animal model) have been shown to exhibit biased contralateral (to the lesion) swing activity (Borlongan \& Sanberg, 1995), whereas animals with neurotoxic lesions in the striatum (a Huntington's disease, HD, animal model) have been shown to display biased ipsilateral swing activity (Borlongan, Randall, et al., 1995).

Positive effects of fetal neural transplantation in animal models of HD have prompted several researchers to start early clinical trials for HD (Philpott et al., 1997). In most unilateral excitotoxic animal models of $\mathrm{HD}$, the druginduced rotation test has been similarly employed as the behavioral index for transplant-induced normalization of motor asymmetry (Borlongan, Randall, et al., 1995; Sanberg, Wictorin, \& Isacson, 1994). In the present study, we utilized the drug-free EBST to demonstrate whether or not such test can characterize the amelioration of asymmetrical motor behavior following transplantation of fetal striatal tissue (lateral ganglionic eminence, LGE) into the unilateral ibotenic acid (IA)-lesioned striatum of young adult rats. The behavioral symptoms induced by IA resemble many of the features of HD (Isacson, Brundin, Gage, \& Björklund, 1985).

\section{METHOD}

\footnotetext{
Animals

Twenty male, Sprague-Dawley 8-week-old rats (Harlan SpragueDawley, Indianapolis) were used as subjects. The animals were housed in pairs in a room with controlled temperature and humidity
} 


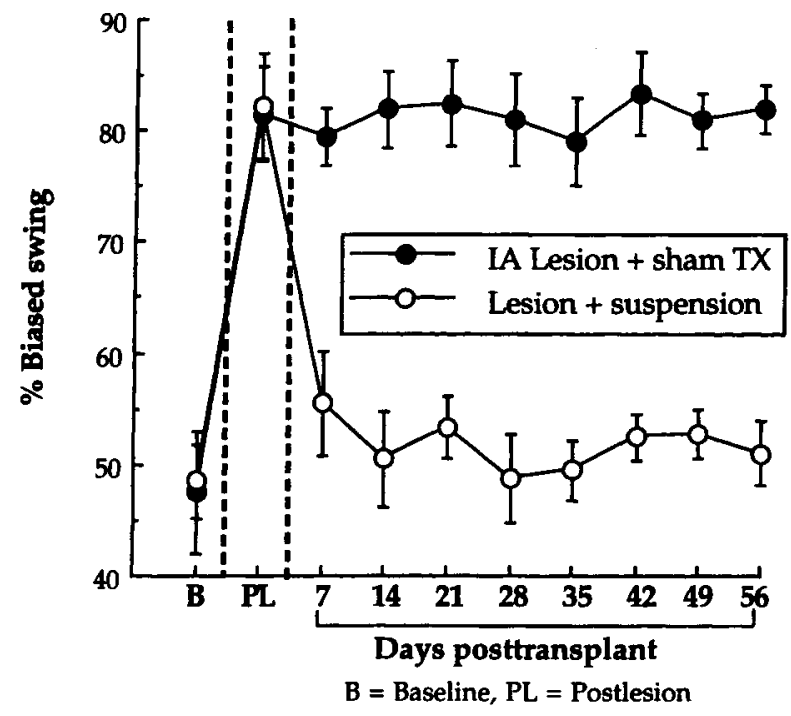

Figure 1. Elevated body swing test. At baseline (prelesion), animals (plotted data) exhibited unbiased swing behavior (about $50 \%$ left and right swings). At 2 months postlesion, all animals exhibited biased swing behavior ( $>70 \%$ ipsilateral to the lesion). Animals that received fetal striatal transplants showed normalization of swing behavior compared with animals that received the vehicle alone.

and were maintained in a 12:12-h light:dark cycle. The animals had free access to food and water in their house cages. Baseline data for the swing behavior (see below) were obtained 2 days after arrival. Sixteen animals that displayed unbiased behavior (40\%-60\% swing to either the left or the right side) were included in the study.

\section{Surgical Procedures}

Lesion protocol. The body temperature of the animals was kept at normal limits throughout the surgical procedure. Body weights of the animals and general condition were monitored daily. The rats were first anesthetized with sodium pentobarbital $(70 \mathrm{mg} / \mathrm{kg}$, i.p.) and then mounted on a Kopf stereotaxic device. Stereotaxic coordinates were based from the bregma point with the tooth bar adjusted at the level of the interaural line. The experimental animals that showed unbiased swing activity were stereotaxically lesioned in the right striatum $(\mathrm{AP}=+1.2 ; \mathrm{ML}=-2.8 ; \mathrm{DV}=-5.5)$. The animals received $50 \mu \mathrm{g}$ of IA (Sigma Chemical) in $2 \mu \mathrm{l}$ of $0.9 \%$ saline with the $\mathrm{pH}$ adjusted to 7.4 using $6 \mathrm{M} \mathrm{NaOH}$.

Transplant protocol. At 2 months postlesion, the transplantation of rat fetal striatal cell suspension was conducted. All surgical procedures were done in aseptic conditions. A Hamilton syringe was used to inject the cell suspension at the same coordinates as those for the neurotoxic lesion. Preparation and dissection of the rat fetal lateral eminence (gestational ages 14-15) followed the procedures described by Pakzaban, Deacon, Burns, and Isacson (1993). Briefly, trypsin was used to enzymatically and then mechanically dissociate the dissected tissues into a cell suspension. Approximately two striatal anlages per lesioned host striatum were transplanted. This coincides to 480,000 viable rat cells. A hemocytometer (Brundin, Isacson, \& Björklund, 1985) with viability stain (tryphan blue) was used to count the exact number and viability of transplanted cells. Randomly selected rats $(n=8)$ that received striatal transplants were first anesthetized with sodium pentobarbital $(70 \mathrm{mg} / \mathrm{kg}$, i.p.) and then mounted in the Kopf stereotaxic device. A total of $3 \mu \mathrm{l}$ of cells in medium were infused over $5 \mathrm{~min}$. Following the transplantation, the animals were placed on a heating pad until recovery. The remaining animals were introduced to the same surgical procedures, except that hibernation medium alone was infused into the striatum. To ensure normal health conditions for the animals, body weights and general condition were monitored daily.

Behavioral test. The animals were tested in the EBST (Borlongan, Randall, et al., 1995; Borlongan \& Sanberg, 1995) at 2 months postlesion, at 7 days posttransplant, and once a week thereafter up to 56 days. Briefly, the animal was placed in a Plexiglas box $(40 \times 40$ $\times 35 \mathrm{~cm}$ ) and allowed to habituate for $2 \mathrm{~min}$. The animal was slightly raised an inch above the ground by holding its tail. A swing was counted when the animal moved its head more than $10^{\circ}$ to either side of the vertical axis. The head of the animal had to return to the vertical axis and then deviated by at least $10^{\circ}$ before the next swing was counted. During each test day, individual animals were introduced to a 30-sec EBST. At 2 months postlesion, all 16 animals in the present study showed $70 \%$ or greater ipsilateral (to the lesion) biased swing. In addition, at 2 months postlesion and at 28 days and 56 days posttransplant, all animals were also subjected to apomorphine-induced rotation test $(0.2 \mathrm{mg} / \mathrm{kg}$, i.p.) to validate the sensitivity of the EBST in characterizing the motor dysfunction in lesioned and transplanted animals. A detailed description of the rotation test, the conventional behavioral index of animals with unilateral CNS lesions, has been given elsewhere (Borlongan, Randall, et al., 1995).

\section{Statistical Analysis}

The biased swing responses and the drug-induced rotations were analyzed in separate analyses of variance (ANOVAs) with repeated measures over the postlesion and posttransplant days. Significant differences between the swing behaviors or drug-induced rotations for each test day were analyzed with the use of Bonferroni's correction for multiple comparisons.

\section{RESULTS}

The EBST results revealed that unilateral excitotoxic lesioned animals exhibited ipsilateral (to the lesioned side) biased swing activity at 2 months postlesion (baseline vs. 2 months postlesion, $t=19.13, p<.05, n=14$ ) (Figure 1). Excitotoxic lesioned animals receiving fetal striatal transplants displayed normalization of asymmetrical behavior (about $50 \%$ swings to either side) as early as 7 days posttransplant and throughout the 56-day test period. An ANOVA revealed a significant main treatment effect $[F(1,14)=22.06, p<.05]$, and no significant main days effect or days $\times$ treatment interaction $(p>.05)$. At each test day, animals that received the fetal striatal transplants had significantly marked reduction in their biased swing behavior $(t \mathrm{~s}>5.25, p \mathrm{~s}<.05)$.

The occurrence of the biased swing behavior following the unilateral IA lesions paralleled the observation of apomorphine-induced rotation. All animals exhibited $>175$ turns over $30 \mathrm{~min}$ at 2 months postlesion (Figure 2). Similarly, the normalization of the swing behavior coincided with the reduction in the drug-induced rotation in animals that received fetal striatal cells. At 28 and 56 days posttransplant, all animals receiving fetal striatal cells displayed a significant reduction in their drug-induced rotations (mean $=64 \pm 5.3$ turns per min, $p<.05$ ). All animals that received the vehicle alone maintained their pretransplant level of drug-induced rotations.

Preliminary histological examination revealed a few acetylcholinesterase (AChE)-positive patches in the graft in animals receiving fetal striatal transplants (data not shown). In HD, AChE is markedly reduced (Isacson et al., 


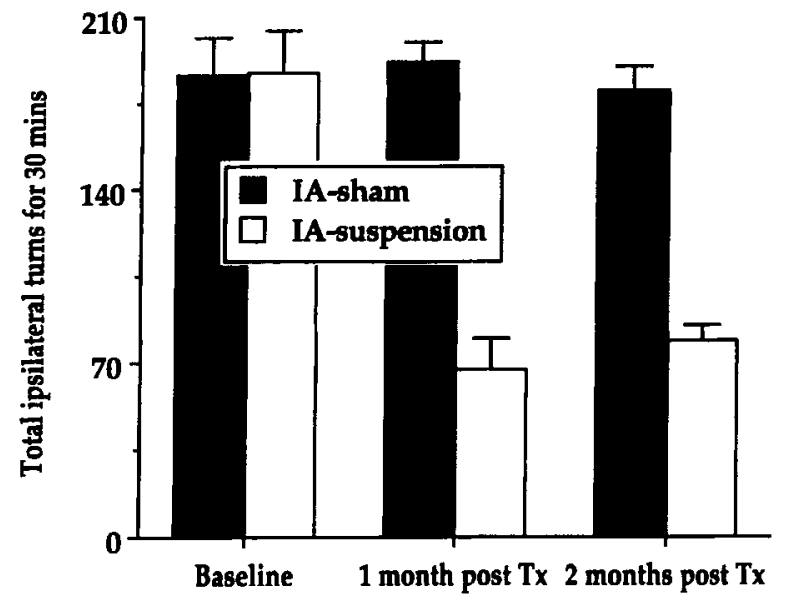

Figure 2. Apomorphine-induced rotations. At baseline ( 2 months postlesion), unilaterally lesioned animals exhibited $>175$ druginduced rotations for $30 \mathrm{~min}$. Following transplantation, animals that received fetal striatal transplants showed significant reduction in their drug-induced rotations compared with animals that received the vehicle alone $(p<.05)$.

1985; Sanberg, Wictorin, \& Isacson, 1994). Although there were only a few AChE-positive patches in our transplanted animals, no visible AChE-positive cells were noted within the medium infusion site of sham transplanted animals. These histological results will be reported elsewhere (Sanberg, Borlongan, Koutouzis, et al., 1997).

\section{DISCUSSION}

The present behavioral study demonstrated a normalization of the biased swing activity in animals receiving fetal striatal transplants. It was shown that the EBST is a sensitive measure of dysfunction and normalization of asymmetrical behavior following excitotoxic lesions and transplantation, respectively.

The present study provides support for fetal striatal transplants for HD. Previously, we reported that rats with unilateral quinolinic acid or 3-nitropropionic acid lesions exhibited significant reductions in the drug-induced rotational test at 1 month after fetal striatal transplants (Borlongan, Randall, et al., 1995). Past studies have similarly demonstrated recovery of drug-induced rotational behavior in excitotoxic lesioned animals following fetal striatal transplants (Isacson et al., 1985; Sanberg \& Coyle, 1984). We further provided support to our previous study, using rats with unilateral 3-nitropropionic acid (Borlongan, Cahill, \& Sanberg, 1995), that the EBST is sensitive to transplantinduced normalization of motor behavior. These results taken together indicate the potential benefits of fetal striatal transplants for HD. Indeed, encouraging results have been reported in early clinical trials of fetal striatal transplantation for HD (Philpott et al., 1997).

The observed behavioral recovery in the present study cannot be ascribed to reconstruction of the damaged host striatum by the transplanted fetal tissue, since, as we have noted in an accompanying study (Sanberg, Borlongan, Koutouzis, et al., 1997), only a few AChE-positive patches were found within the graft. Although other investigators have shown correlation of AChE-positive patches in the graft with the occurrence of behavioral recovery in HD excitotoxic rats (Pundt, Kondoh, Conrad, \& Low, 1996), normalized AChE levels may not be important for simple tasks (Fricker et al., 1997; Sanberg, Borlongan, et al., 1994; Sanberg, Wictorin, \& Isacson, 1994), such as the locomotor behavior in the present study. Alternatively, trophic factors may be released by the graft, which can produce the behavioral recovery at early posttransplantation periods (Borlongan, Polgar, Cahill, Freeman, \& Sanberg, 1996). Of note, the timing of graft maturation, the localized dissection of the graft source (i.e., lateral ganglionic eminence), and the definition of AChE patches matrix may need to be analyzed further in subsequent studies in order to address the validity of AChE staining as a definitive marker for fetal striatal cell graft-induced recovery. Furthermore, additional studies are warranted for the purpose of directly examining any correlation between normalization of asymmetrical behavior as revealed by EBST and neurotransmitter release.

The hibernation medium used in the present study has been shown previously not to affect recovery from the lesion (i.e., delay recovery) nor worsen the lesion (Borlongan, Cahill, \& Sanberg, 1995; Sanberg, Borlongan, et al., 1994; Sanberg, Wictorin, \& Isacson, 1994). Although it has been demonstrated that the hibernation medium used in the present study can prolong in vitro survival/storage of fetal striatal cells following dissection, our previous experiments have provided no evidence that intrastriatal infusion of this medium alone promotes in vivo recovery of lesioned host striatal cells. We are aware, however, that other types of medium containing neurotrophic factors (e.g., GDNF, Borlongan et al., 1996) or the Sertoli cell preconditioned medium (Sanberg, Borlongan, Othberg, et al., 1997; Sanberg, Borlongan, Saporta, \& Cameron, 1996) have the potential to provide neuroprotective effects against, as well as neuronal rescue from, neurotoxin-induced degeneration.

In summary, the EBST offers a drug-free approach to characterize lesion- and transplant-induced motor alterations associated with excitotoxic CNS injury. Repeated exposure of animals to the drug-induced rotational test can be significantly reduced (thus avoiding sensitization problems) by alternate use of the EBST and the rotation test over the experimental test period. Future studies should analyze the possible relationship between transplant maturation and behavioral recovery.

\section{REFERENCES}

Borlongan, C. V., Cahill, D. W., \& Sanberg, P. R. (1995). Asymmetrical behavior in rats following striatal lesions and fetal transplants: The elevated body swing test. Restorative Neurology \& Neuroscience, 9, 15-19.

Borlongan, C. V., Polgar, S., Cahill, D. W., Freeman, T. B., \& SANBERG, P. R. (1996). Will fetal striatal transplants correct the akinetic stage of Huntington's disease? Neurodegeneration, 5, 189-192. 
Borlongan, C. V., Randall, T. S., Cahill, D. W., \& Sanberg, P. R. (1995). Asymmetrical motor behavior in rats with unilateral striatal excitotoxic lesion as revealed by the elevated body swing test. Brain Research, 676, 231-234.

Borlongan, C. V., \& SANBerg, P. R. (1995). Elevated body swing test: A new behavioral parameter for rats with 6-hydroxydopamineinduced hemiparkinsonism. Journal of Neuroscience, 15, 1532-1537.

BRundin, P., IsACson, O., \& BJörKLund, A. (1985). Monitoring of cell viability of embryonic CNS tissue and its use as a criterion for intracerebral graft survival. Brain Research, 331, 251-259.

Fricker, R. A., Torres, E. M., Hume, S. P., Myers, R., OpackaJufFrey, J., ASHWORTh, S., BroOKS, D. J., \& DunNeTt, S. B. (1997) The effects of donor stage on the survival and function of embryonic striatal grafts in the adult rat brain: II. Correlation between positron emission tomography and reaching behaviour. Neuroscience, 79, 711-721.

Hattori, S., Li, Q., Matsui, N., \& Nishino, H. (1993). Treadmill running test for evaluating locomotor activity after 6-OHDA lesions and dopaminergic cell grafts in the rat. Brain Research Bulletin, 31, 433-435.

Isacson, O., Brundin, P., GAGE, F. H., \& BJörklund, A. (1985). Neural grafting in a rat model of Huntington's disease: Progressive neurochemical changes affecting neostriatal ibotenate lesions and striatal tissue grafting. Neuroscience, 16, 799-817.

KolB, B., \& WhishaW, I. Q. (1985). An observer's view of locomotor asymmetry in the rat. Neurobehavioral Toxicology \& Teratology, 7, 71-78.

Norman, A. B., Calderon, S. F., Giordano, M., \& Sanberg, P. R. (1988). A novel rotational behavior model for assessing the restructuring of striatal dopamine effector systems: Are transplants sensitive to peripherally acting drugs? In D. M. Gash \& J. R. Sladek, Jr. (Eds.), Transplantation into the mammalian CNS (Progress in Brain Research, Vol. 78, pp. 61-67). Amsterdam: Elsevier.

Pakzaban, P., Deacon, T. W., BuRns, L. H., \& Isacson, O. (1993). Increased proportion of AChE-rich zones and improved morphological integration in host striatum of fetal grafts derived from the lateral but not the medial ganglionic eminence. Experimental Brain Research, 97, 13-22.

Philpott, L. M., Kopyov, O. V., Lee, A. J., Jacques, S., Duma, C. M., CAINE, S., YANG, M., \& EAGLE, K. S. (1997). Neuropsychological functioning following fetal striatal transplantation in Huntington's chorea: Three case presentations. Cell Transplantation, 6, 203-212.

Pundt, L. L., Kondoh, T., ConRad, J. A., \& Low, W. C. (1996). Transplantation of human striatal tissue into a rodent model of Huntington's disease: Phenotypic expression of transplanted neurons and host-tograft innervation. Brain Research Bulletin, 39, 23-32.

Sanberg, P. R., Borlongan, C. V., Freeman, T. B., Cahill, D. W., IsACSON, O., \& PAKZABAN, P. (1994). Transplantation of striatal human fetal tissue in excitotoxin model of Huntington's disease: Neuroanatomical and behavioral effects. Society for Neuroscience Abstracts, 20,470 .

Sanberg, P. R., Borlongan, C. V., Koutouzis, T. K., Cahill, D. W., NoRgren, R., \& FreEman, T. B. (1997). Human fetal tissue transplantation in an excitotoxic rat model of Huntington's disease. In A. Prokop, D. Hunkeler, \& A. D. Cherrington (Eds.), Bioartificial organs (Annals of the New York Academy of Sciences, Vol. 831, pp. 452460). New York: New York Academy of Sciences.

Sanberg, P. R., Borlongan, C. V., Othberg, A. I., Saporta, S., Freeman, T. B., \& CAMERon, D. F. (1997). Testis-derived Sertoli cells have a trophic effect on dopamine neurons and alleviate hemiparkinsonism in rats. Nature Medicine, 3, 1129-1132.

Sanberg, P. R., Borlongan, C. V., Saporta, S., \& Cameron, D. F. (1996). Testis-derived Sertoli cells survive and provide localized immunoprotection for xenografts in rat brain. Nature Biotechnology, 14, 1692-1695.

SANBERG, P. R., \& COYLE, J. T. (1984). Scientific approaches to Huntington's disease. CRC Critical Reviews in Clinical Neurobiology, 1, 1-44.

SANBERG, P. R., Wictorin, K., \& IsaCsON, O. (1994). Huntington's disease. In P. R. Sanberg, K. Wiktorin, \& O. Isacson (Eds.), Cell transplantation for Huntington's disease (pp. 1-124). Boca Raton, FL: CRC Press.

UNGERSTEDT, U., \& ARBUTHNOTT, G. W. (1972). Quantitative recording of rotational behavior in rats after 6-hydroxydopamine lesions of the nigrostriatal dopamine system. Brain Research, 24, 485-493.

(Manuscript received March 21, 1997; revision accepted for publication December 10, 1997.) 